\title{
Living in a Dangerous Climate: Climate Change and Human Evolution
}

\author{
Renee Hetherington. 2012. Cambridge University Press, Cambridge. Pp.256, 14 illustrations. $\$ 95.00$ (hardcover). \\ ISBN 978-1107694736.
}

Reviewed by Matt Law

Reviewer address: School of Society, Enterprise and Environment, Bath Spa University, Cardiff, UK m.law@bathspa.ac.uk

Received: February 28, 2014

Volume 5:42-43

Published: April 7, 2014

(C) 2014 Society of Ethnobiology

In the decade that atmospheric levels of $\mathrm{CO}_{2}$ passed 400 parts per million ( $\mathrm{ppm}$ ) for the first time since the Pliocene, interest in how past human (and hominin) societies adapted to environmental change seems greater than ever. Recent books like Miller et al. (2011), Sheets and Cooper (2012), and van der Noort (2013) set the tone, providing sustainability lessons from archaeological examples. This book follows on from a previous work, Hetherington and Reid (2010), essentially distilling parts of that book to make them more easily accessible for a wider audience.

After an initial chapter that sets out the book's central arguments, we are taken on a whistle-stop tour of human evolution. As an accessible summary, it works very well, with helpful illustrations and tables. Recent findings about Homo floresiensis are deftly integrated, making this a valuable resource for public engagement, although it is only a brief summary those looking for an accessible account of human evolution with more detail may wish to look at Roberts (2010) or Stringer (2012). Hetherington takes the opportunity to make some serious points in a fun way: chapter 3, 'The Neanderthal Enigma', begins with a vivid description of the depiction of Neanderthals as simple savages that will be familiar to many, before casting that story in the light of history written by the triumphant (i.e., Homo sapiens), presenting archaeological evidence that Neanderthals were far from simple.

Two chapters on how climate may have influenced human migration follow, describing how the spread of $H$. sapiens coincided with the onset of a cold stage and the ensuing advancement of desert into southern and eastern Africa. All is not environmentally determined, however: Hetherington does note that population increases or disease may have been the catalyst to spur human migration. As might be expected from an author in the Americas, there is a whole chapter dedicated to the peopling of the Americas, again engagingly woven with recent archaeological findings.

The next chapter deals ably, but briefly, with the emergence of agriculture and animal domestication, with an excellent table that gives the timing and location of the first domestication of various important plant and animal species, which will certainly make a useful reference. Here climate is given the lion's share of credit for the emergence of stable societies and farming, rather than social factors.

Again, the focus switches back to the Americas for a whole (if short) chapter, specifically the Maya, who are described as having tried to adapt to climate change but unsuccessfully. Here, an opportunity to expand on some of the other civilisations whose collapses have been, partially or wholly, attributed to climate change is missed, such as the Mycenaeans, the Khmer empire, the Tang dynasty, the Egyptian New Kingdom, or, within the Americas, the Moche and the Tiwanaku.

The summary of human evolution and migration and the emergence of agriculture at this point gives way to the real meat of the book, which diverges into a more polemical essay. Hetherington characterizes the Social Darwinian concept of "survival of the fittest", which is incorporated into many western value systems, as being detrimental to the future of humanity. She is keen to emphasise that dominant species can cease to be dominant, and that there is a paradox at the heart of modern humanity: although we have successfully adapted to climate change in the past, we are now so sheltered from nature that our adaptability is compromised. 
At times, this part of the book, particularly the start of the chapter "Darwin the Selector", are deeply personal, giving us small flashes of autobiography that are affecting and admirable in their candour, but it is not always explicit how they are relevant. There are also chapters on two scientists whose work fell afoul of neo-Darwinists, Paul Kammerer and Richard Benedict Goldschmidt, which are illuminating and engagingly written, but again questionably relevant.

There is an important argument being made, however, with essential points about the need to stop seeing ourselves as detached from nature, and to embrace the diversity of worldviews that humanity encompasses. Despite the excellent and clear writing, this is very much a book of two halves, and it is somewhat difficult to reconcile the two. The first half feels more like an introductory course book, the second will have more value to scholars as a political argument alongside the likes of Giddens (2012).

Ethnobiologists, especially those concerned with the role of environmental interactions in the history of human evolution and the development of farming, will find this book useful. In particular, the synthesis of recent research is especially enjoyable, and supported by an extensive bibliography and informative endnotes. The book also stands as an important example of how palaeoanthropological and ethnobi- ological perspectives can be brought to bear on the question of what to do about surviving climate change.

\section{References cited}

Giddens, A. 2012. The Politics of Climate Change. Second Edition. Polity, Cambridge.

Hetherington, R. and R. Reid. 2010. The Climate Connection: Climate Change and Modern Human Evolution. Cambridge University Press, Cambridge.

Miller, N. F., K.M. Moore and K. Ryan, eds. 2011. Sustainable Lifeways: Cultural Persistence in an EverChanging Environment. University of Pennsylvania Press, Philadelphia.

Roberts, A. 2010. The Incredible Human Journey. BBC: London.

Sheets, P. and J. Cooper. 2012. Surviving Sudden Environmental Change: Answers From Archaeology. University of Colorado Press, Boulder.

Stringer, C. 2013. The Origin of Our Species. Penguin, London.

Van der Noort, R. 2013. Climate Change Archaeology: Building Resilience from Research in the World's Coastal Wetlands. Oxford University Press, Oxford. 